\title{
Ecological Studies of Transformed Trichoderma harzianum Strain 1295-22 in the Rhizosphere and on the Phylloplane of Creeping Bentgrass
}

\author{
C.-T. Lo, E. B. Nelson, C. K. Hayes, and G. E. Harman
}

First, third, and fourth authors: Departments of Plant Pathology and Horticultural Sciences, Cornell University, Geneva, NY 14456; second author: Department of Plant Pathology, Cornell University, Ithaca, NY 14853.

Permanent address of C.-T. Lo: Taiwan Agricultural Research Institute, Department of Plant Pathology, 189 Chung-Cheng Rd., Wu-Feng 41301, Taichung Taiwan, Republic of China.

Accepted for publication 22 October 1997.

\begin{abstract}
Lo, C.-T., Nelson, E. B., Hayes, C. K., and Harman, G. E. 1998. Ecological studies of transformed Trichoderma harzianum strain 1295-22 in the rhizosphere and on the phylloplane of creeping bentgrass. Phytopathology 88:129-136.

A $\beta$-glucuronidase $(G U S)$ reporter gene and a hygromycin B (hygB) phosphotransferase gene were integrated separately into the Trichoderma harzianum strain 1295-22 genome, using biolistic transformation. The mycelial growth and biocontrol ability of the transformed strains did not differ from that of the original strain. The transformed Gus ${ }^{+}$-kanamycinresistant $\left(\mathrm{Gus}^{+} \mathrm{Kan}^{\mathrm{R}}\right)$ strains were used to monitor growth and interactions with Rhizoctonia solani on creeping bentgrass plants. The hygBresistant $\left(\right.$ hygB ${ }^{\mathrm{R}}$ ) strains were used to selectively recover strain 1295-22 from the rhizosphere soil and phylloplane of creeping bentgrass after spray applications. The population levels of two hyg $\mathrm{B}^{\mathrm{R}}$ strains and the original strain were very similar for all treatments. All three strains persisted for

of the experiment in unautoclaved soils. In this study, the results demonstrated that hygB $\mathrm{B}^{\mathrm{R}}$ strains remained dominant over time when assayed on Trichoderma-selective medium containing hygB. The hygB ${ }^{\mathrm{R}}$ strains were not displaced by strains that colonized untreated plants. Microscopic observation showed that the Gus ${ }^{+} \operatorname{Kan}^{\mathrm{R}}$ strains colonized the rhizoplane, seed coat, and phylloplane of creeping bentgrass. These results supported our earlier observation that strain 1295-22 was rhizosphere and phylloplane competent. Interactions between $T$. harzianum and $R$. solani were readily observed in situ and changed over time. Two types of reactions were found in these experiments. In the first type, sections of hyphae of $R$. solani near the hyphae of T. harzianum appeared damaged, and the pathogen appeared necrotic when viewed with a microscope. The second type, observed less frequently than the first type, was typical of mycoparasitism. The findings in this study provide new insight into the interactions between $R$. solani and T. harzianum, providing a basis for future research.
\end{abstract} the duration of the experiment ( 28 days) in both the rhizosphere soil and on leaves, although population levels declined somewhat over the course

Trichoderma harzianum Rifai has been used as a biocontrol agent to protect plants against root, seed, and foliar diseases and storage rots $(1,10)$. Results from field trials indicate that isolates of the biocontrol agent work well under different environmental conditions, protecting several crops, as well as controlling various plant pathogens (5). However, a number of T. harzianum strains must be selected for their activity against pathogens on different crops, because the survival traits of these strains may be strongly influenced by crop-specific environmental factors (27). To predictably and successfully use biocontrol agents for disease control, it is critical that their biology and ecology be more completely understood.

Biocontrol agents differ fundamentally from chemical fungicides in that they must grow and proliferate to be effective (25). Therefore, effective antagonists must become established in crop ecosystems and remain active against target pathogens during periods favorable for plant infection. The survival ability of biocontrol agents, including population size, survival period, and distribution in or on crops, needs to be surveyed and associated with biocontrol effects.

Numerous methods for assessing populations, activity, and biomass have been developed (28), but problems arise from the inability to detect, monitor, and recover specific microorganisms. For example, dilution-plating on selective media often has been

Corresponding author: G. E. Harman; E-mail address: geh3@ cornell.edu

Publication no. P-1997-1211-01R

(C) 1998 The American Phytopathological Society

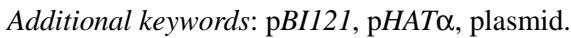

used for quantitative isolation of Trichoderma spp. from soil (35). However, introduced strains are difficult to distinguish from indigenous strains. Moreover, the distribution of the biocontrol agent is difficult to ascertain on crop plants. The use of mutant strains resistant to specific toxicants has partially overcome these problems (2).

More recently, production of transformed strains containing reporter or marker genes in the fungal genome has provided a new tool for detection and monitoring $(6,13,26,36)$. For example, the hygromycin $\mathrm{B}($ hygB $)$ phosphotransferase gene coding for hygB resistance $\left(\mathrm{hygB}^{\mathrm{R}}\right)$ has been used to detect the survival of biocontrol agents on the tomato phylloplane (24). The $\beta$-glucuronidase $(G U S)$ reporter gene from Escherichia coli also is promising for use in ecological studies (8), because the enzyme is fairly stable and can be assayed easily by different methods (15-17). GUS transformants of several plant-pathogenic fungi have been used for detection and biomass quantification in infected plant tissue $(6,26)$.

T. harzianum strain 1295-22 has been reported to be rhizosphere and phylloplane competent and to effectively control several plant pathogens $(12,20,23)$. In situ, however, the survival ability and distribution of this strain in soils and on plant tissues has not been described and distinguished from natural Trichoderma spp. The interaction between strain 1295-22 and pathogens in and on plant tissues also has not been determined. In this study, the objectives were (i) to produce transformants of $T$. harzianum 1295-22 that were $\operatorname{hygB}^{\mathrm{R}}$ or that expressed GUS, (ii) to determine whether hyg $\mathrm{B}^{\mathrm{R}}$ transformants have the same level of biocontrol ability and ecological fitness as the wild strain, (iii) to determine where transformants of strain 1295-22 expressing GUS (Gus ${ }^{+}$-kanamycin re- 
sistant $\left[\mathrm{Gus}^{+} \mathrm{Kan}^{\mathrm{R}}\right]$ ) colonize leaves and roots of turfgrass, and (iv) to observe the interaction between the $\mathrm{Gus}^{+} \mathrm{Kan}^{\mathrm{R}}$ transformants and pathogens on turfgrass.

\section{MATERIALS AND METHODS}

Fungal strains and media. T. harzianum strain 1295-22 (ATCC 20847) was used throughout this study as the wild-type. It was obtained by protoplast fusion of T. harzianum strains T-12 (ATCC 74058) and T-95 (ATCC 60850) (17). This strain, unless otherwise noted, was cultured on potato dextrose agar (PDA) (Difco Laboratories, Detroit) and maintained on silica gel at $-20^{\circ} \mathrm{C}$ until use.

Two types of transformants were produced and used for this study. One type was resistant to hygB and was used for testing strain survival in rhizosphere soil and on the phylloplane of creeping bentgrass (Agrostis palustris Huds). The other type, a $\mathrm{Kan}^{\mathrm{R}}$ strain that expressed GUS $\left(\mathrm{Gus}^{+} \operatorname{Kan}^{\mathrm{R}}\right.$ ), was used for detecting plant colonization and examining in situ the interaction between pathogens on creeping bentgrass plants. These transformed strains were maintained on PDA at $4^{\circ} \mathrm{C}$ until use.

Transformation vectors. The two plasmids used in these studies were $\mathrm{pHAT} \alpha$ (29) and $\mathrm{p} B I 121$ (Clonetech Laboratories Inc., Palo Alto, CA). Plasmid $\mathrm{p} B 1121$ contains a GUS gene driven by the cauliflower mosaic virus $35 \mathrm{~S}$ promoter $(\mathrm{CaMV} 35 \mathrm{~S})$ and a $\mathrm{Kan}^{R}$ gene driven by the $N O S$ promoter. pHAT $\alpha$ contains a $h y g B^{R}$ gene driven by the Aspergillus nidulans gpd promoter (13). These plasmids were isolated following standard protocols (31), maintained in $E$. coli, and kept at 4 or $-20^{\circ} \mathrm{C}$ until use.

Preparation of cells and microprojectiles for bombardment and biolistic transformation. Conidia of strain 1295-22 were transformed by biolistic methods, as described by Lorito et al. (22). Briefly, 7- to 10-day-old conidia harvested from PDA plates were suspended in sterile water and adjusted to $10^{8}$ conidia per ml. Conidial suspensions $(100 \mu \mathrm{l})$ were spread evenly over a 9 -cm-diameter petri dish filled with $10 \mathrm{ml}$ of PDA containing $0.1 \%$ Igepal630 (Alltech Associates Inc., Deerfield, IL). The surfaces of the plates were briefly air-dried under sterile conditions and used within 0.5 to $1 \mathrm{~h}$. Plasmid DNA from either $\mathrm{pHAT} \alpha$ or $\mathrm{p} B I 121$ was precipitated onto M5 tungsten particles (1.07 $\mu \mathrm{m}$ mean diameter; Sylvania, GTE Products Corp., Towand, PA), following the procedure of Sanford et al. (32) with minor variations. Aliquots sufficient for 12 bombardments were prepared in $100 \%$ ethanol, and $8 \mu \mathrm{l}(\approx 0.8 \mu \mathrm{g}$ of DNA associated with $\approx 500 \mu \mathrm{g}$ of tungsten $)$ was spread on the launch surface for each shot. For the bombardment, the distance between the helium source and the launch mechanism was $1.6 \mathrm{~cm}$, and the target plates were placed $6 \mathrm{~cm}$ from the launch site. The chamber was flushed for $10 \mathrm{~s}$ with helium, and a partial vacuum of $74 \mathrm{~cm}$ of mercury was applied. The tungsten particles with plasmid DNA were launched into the conidia of strain $1295-22$ with helium pressure at $84 \mathrm{~kg} / \mathrm{cm}^{2}(22,32)$. The bombarded plates were incubated at $25^{\circ} \mathrm{C}$ for 6 to $8 \mathrm{~h}$ and treated, using the following procedure to select the expected transformants.

Selection of transformants. To select the hygB ${ }^{\mathrm{R}}$ strains, PDA plates containing hygB at $700 \mu \mathrm{g} / \mathrm{ml}$ (Boehringer Mannheim, Indianapolis, IN) were used. PDA plates containing Kan at 3,000 $\mu \mathrm{g} / \mathrm{ml}$ (Fisher, Fair Lawn, NJ) were used for selection of $\operatorname{Kan}^{\mathrm{R}}$ strains expressing GUS.

For selection of hygB ${ }^{\mathrm{R}}$ strains, a 10 -ml agar overlay solution containing hygB at $1,400 \mu \mathrm{g} / \mathrm{ml}$ was layered onto the surface of PDA plates 6 to $8 \mathrm{~h}$ after bombardment with $\mathrm{pHAT} \alpha$. Colonies that had grown to the surface of the selective medium were removed 36 to $48 \mathrm{~h}$ after incubation at $25^{\circ} \mathrm{C}$ and transferred to PDA plates containing hygB at $700 \mu \mathrm{g} / \mathrm{ml}$.

After transformation with plasmid pBI121, a 10-ml agar overlay solution containing Kan at $6,000 \mu \mathrm{g} / \mathrm{ml}$ was layered on the surface of the bombarded plates. After 36 to $48 \mathrm{~h}$, the colonies that reached the surface of the medium were transferred to fresh PDA plates containing Kan at $3,000 \mu \mathrm{g} / \mathrm{ml}$. A piece of mycelia from each colony was placed in an Eppendorf tube containing $100 \mu \mathrm{l}$ of 5-bromo-4-chloro-3-indolyl- $\beta$-D-glucuronic acid (X-Gluc) at $1 \mathrm{mg} / \mathrm{ml}$ (Sigma Chemical Co., St. Louis, or Clonetech) in phosphate buffer solution for $48 \mathrm{~h}$ (37). Strains that turned blue were selected for further tests.

Selected transformants of T. harzianum 1295-22 were allowed to sporulate, and new colonies were derived from single conidia to obtain homokaryotic transformants. $\mathrm{HygB}^{\mathrm{R}}$ homokaryons of $T$. harzianum were obtained by plating on hyg-selection plates (PDA amended with hygB at $700 \mu \mathrm{g} / \mathrm{ml}$ ).

Homokaryotic GUS transformants were obtained from colonies developed from single conidia by plating on Czapek-Dox agar (CDA) plates supplemented with X-Gluc at $500 \mu \mathrm{g} / \mathrm{ml}$ and Kan at $3,000 \mu \mathrm{g} / \mathrm{ml}$ (26). Colonies that developed blue pigment were transferred to PDA amended with Kan at 3,000 $\mu \mathrm{g} / \mathrm{ml}$.

Selected hygB ${ }^{\mathrm{R}}$ or $\mathrm{Gus}^{+} \mathrm{Kan}^{\mathrm{R}}$ strains isolated after three successive single-spore generations on selective media were subjected to dot blot and Southern blot hybridizations to confirm transformation and integration of the transforming DNA into the 1295-22 genome. The GUS gene was labeled with the DNA labeling and detection kit (Boehringer Mannheim) by polymerase chain reaction with primers that were specific for the $5^{\prime}$ and $3^{\prime}$ ends of this gene. The $h y g B$ gene was removed from plasmid pAN7-1 as a HindIII$E c o$ RI fragment that was electroeluted and labeled with the aforementioned kit, using random primers. Genomic DNA extracted from the fungal isolates grown in potato dextrose broth plus hygB at $700 \mu \mathrm{g} / \mathrm{ml}$ for strains T22/H038 and T22/H094 (hygB ${ }^{\mathrm{R}}$ strains) or Kan at 3,000 $\mu \mathrm{g} / \mathrm{ml}$ for $\mathrm{Gus}^{+}$strains were isolated following the procedure of Raeder and Broda (30). Dot blots and Southern blots were performed following standard procedures (31).

Comparison of the growth rates of strain 1295-22 of $T$. harzianum and its transformants. The morphology and mycelial growth rate of hygB ${ }^{\mathrm{R}}$ isolates and $\mathrm{Gus}^{+} \mathrm{Kan}^{\mathrm{R}}$ isolates were compared to the original strain 1295-22. PDA and CDA were inoculated with mycelial disks $(0.3 \mathrm{~cm}$ diameter $)$ of these strains and incubated at both 15 and $30^{\circ} \mathrm{C}$ for 3 days in constant light. The radial growth was recorded every day, beginning $12 \mathrm{~h}$ after inoculation. There were five replicates, and each experiment was performed twice. The strains with morphologies and mycelial growth rates similar to strain 1295-22 were used for further survival and colonization tests.

Comparison of the biocontrol abilities of strain 1295-22 of $T$. harzianum and the transformants. Sphagnum peat moss (Heveco Ltd., Tabusintac, New Brunswick, Canada) was placed in a shallow flat $(50 \times 30 \times 5 \mathrm{~cm})$, and the surface was smoothed. Seeds of creeping bentgrass were sown over the surface as described by Lo et al. (19). The flat was maintained in a greenhouse at 20 to $25^{\circ} \mathrm{C}$ and watered daily. The grass was cut weekly with scissors to a height of $1.5 \mathrm{~cm}$, and the clippings were removed. After 10 days, seedlings were inoculated with Rhizoctonia solani Kühn strain RS-2. Inoculum $(0.2 \mathrm{~g})$ was placed on two opposite corners of the flat. When symptoms appeared, $50 \mathrm{ml}$ of Trichoderma conidial suspensions $\left(10^{7}\right.$ conidia per $\left.\mathrm{ml}\right)$ of the transformed strains (G-83-210, T22/H038, and T22/H094) and strain 1295-22 were each sprayed weekly on seedlings in separate flats. Conidia were harvested by washing PDA plates with sterile distilled water after incubating strains at $25^{\circ} \mathrm{C}$ for 7 days. Conidial suspensions were mixed with $0.1 \%$ (vol/vol) Triton X-100 (Sigma) before spraying. Numbers of conidia were determined by counting in a Petroff-Hausser chamber (C. A. Hausser \& Son, Philadelphia). Biocontrol efficacy was determined over time by estimating the percentage of the flat occupied by diseased plants. The experiment was conducted three times, each with three replicates.

Evaluation of the survival ability of 1295-22 and hygB $^{\mathrm{R}}$ transformants in the rhizosphere or on the phylloplane of creeping bentgrass. Either natural or autoclaved sandy loam soil $(\mathrm{pH} \mathrm{6.3)}$ was placed in plastic boxes $(10 \times 10 \times 5 \mathrm{~cm})$ and evenly sown with creeping bentgrass seeds. These soil boxes were incubated in a growth chamber at $25^{\circ} \mathrm{C}$, with relative humidity varying be- 
tween 60 and $80 \%$ and diurnal light conditions (12 h of dark per $12 \mathrm{~h}$ of light) maintained at $6,000 \mathrm{~lx}$.

T. harzianum strains $1295-22, \mathrm{~T} 22 / \mathrm{H} 038$, and T22/H094 were grown on PDA at $25^{\circ} \mathrm{C}$ under constant light. After 7 days, conidia were harvested by washing each petri dish with $20 \mathrm{ml}$ of sterile distilled water. The resulting spore suspensions were filtered through four layers of cheesecloth (20) and diluted to a final cell density of $10^{7}$ conidia per ml.

For qualitative determinations of colonization on creeping bentgrass, each box was sprayed with conidial suspensions $(20 \mathrm{ml}$ per box, three boxes per isolate) 10 to 14 days after seeds were sown. This volume of spray was sufficient to cover the leaf blades and runoff onto the soil. Ten creeping bentgrass seedlings were removed with sterile forceps $3 \mathrm{~h}$ after treatment and again 3, 5, and 7 days later. The seedlings were immediately rinsed three times with $10 \mathrm{ml}$ of sterile distilled water. Test plants were placed on Trichoderma-selective medium (TSM) or TSM plus hygB at $700 \mu \mathrm{g} / \mathrm{ml}$ for hygB ${ }^{\mathrm{R}}$ strains. After 5 to 10 days of incubation at room temperature, each creeping bentgrass seedling colonized by strain $1295-22$ or hygB ${ }^{\mathrm{R}}$ transformants was recorded.

Quantitative determinations of Trichoderma levels in the rhizosphere soil and on the phylloplane of creeping bentgrass were made based on plants grown in either autoclaved or unautoclaved soils. Soils (200 g) were treated as described above and placed in $10 \times 10 \times 5$-cm plastic boxes. Each soil box was moistened with $36 \mathrm{ml}$ of distilled water at the beginning of the experiments and incubated for $24 \mathrm{~h}$. The creeping bentgrass seeds were sown by sprinkling seeds over the surface of the boxes. Three boxes were seeded for each treatment, and each box was considered a replicate. Each treatment was put into a large transparent plastic box $(32 \times 26 \times 10 \mathrm{~cm})$ to maintain a high relative humidity. Additional water was added as required during this experiment, and experiments were conducted at 23 to $25^{\circ} \mathrm{C}$, with daily light conditions maintained at 6,000 lx. After 10 days, seedlings were sprayed with conidial suspensions until runoff. The experiment was conducted twice.

The conidial suspensions of the above isolates were harvested from the PDA cultures and filtered through four layers of cheesecloth. Suspensions were adjusted to a final cell density of $10^{7}$ conidia per $\mathrm{ml}$ before use. The conidial suspensions of strain 1295-22 or hygB ${ }^{\mathrm{R}}$ transformants were mixed separately with $0.1 \%$ (vol $/ \mathrm{vol}$ ) Triton $\mathrm{X}-100$, and $20 \mathrm{ml}$ of this mixture was applied to each box (20). At timed intervals after treatment, $3 \mathrm{~h}$ and $7,14,21$, and 28 days, $50 \mathrm{mg}$ of air-dried bentgrass leaves from each treatment was harvested and cut into 0.3 - to $0.5-\mathrm{cm}$ pieces with a sterile knife. These leaves were placed in $10 \mathrm{ml}$ of sterile distilled water and vigorously shaken for $3 \mathrm{~min}$ with a vortex shaker. These aqueous samples were serially diluted in sterile distilled water and plated on TSM or TSM plus hygB at $700 \mu \mathrm{g} / \mathrm{ml}$. There were three replicates of each treatment. After incubation for 5 to 7 days at room temperature, colony counts from quadruplicate plates were converted to colony-forming units per $50 \mathrm{mg}$ fresh weight of creeping bentgrass leaves. In the same experiment, soil samples of each treatment also were collected from each box and serially diluted to obtain colony-forming unit counts per gram dry weight of rhizosphere soil.

Colonization and distribution of T. harzianum strains on creeping bentgrass. In one test, strains G83-1-210 and G84-21-208 $\left(\mathrm{Gus}^{+} \mathrm{Kan}^{\mathrm{R}}\right)$ were mixed into sandy loam soil $(\mathrm{pH}$ 6.4) to give $10^{6}$ conidia per $\mathrm{g}$ of soil. The soil was sown with creeping bentgrass seeds and placed in a growth chamber at 23 to $25^{\circ} \mathrm{C}$. Samples of whole seedlings were taken 3, 5, 7, and 10 days after treatment. Seedlings were washed twice with sterile water, and individual plants were placed in Eppendorf tubes containing $100 \mu \mathrm{l}$ of a $1 \mathrm{mg} / \mathrm{ml}$ concentration of X-Gluc in phosphate buffer solution (pH 7) (15). Tubes were incubated in darkness at $30^{\circ} \mathrm{C}$ for at least $16 \mathrm{~h}$, and roots, seeds, and leaves were observed microscopically to detect the presence of Gus ${ }^{+}$hyphae, which appeared blue.
In separate experiments, 5-day-old seedlings were sprayed with spore suspensions of G83-1-210. Seedlings were sampled 1, 2, 3, 5 , and 7 days after treatment. The samples were treated as described above to detect transformants on leaves and roots of plants.

Interactions between 1295-22, GUS transformants, and pathogens. $R$. solani was inoculated at the corner of separate flats $(51 \times$ $26 \times 7 \mathrm{~cm}$ ) containing creeping bentgrass, as described by Lo et al. (20). Spore suspensions (50 ml) of strain 1295-22 or G83-1-210 containing $0.1 \%$ Triton X-100 were sprayed separately on bentgrass when disease symptoms appeared. Samples of turfgrass were taken from or near diseased plants and microscopically observed at 3 and 5 days after treatment.

Experimental design and data analysis. All laboratory and growth-chamber experiments were established as randomized complete block designs with at least three replicates. All data were submitted to analyses of variance, and Duncan's multiple range tests were used for mean separations with the Statistical Analysis System program (SAS Institute Inc., Cary, NC).

\section{RESULTS}

Characterization of transformants of Trichoderma harzianum strain 1295-22. Biolistic treatment of conidia of T. harzianum strain 1295-22 with plasmid DNA carrying the hygB gene always produced hygB ${ }^{\mathrm{R}}$ colonies. In our experiments we obtained 12 colonies resistant to hygB at $700 \mu \mathrm{g} / \mathrm{ml}$. No spontaneous hygB ${ }^{\mathrm{R}}$ transformants or mutants were detected in the controls of any of the experiments.

Transformation with $\mathrm{p} B I 121$ gave rise to strains that grew rapidly on PDA containing Kan at 3,000 $\mu \mathrm{g} / \mathrm{ml}$ and $0.1 \%$ Igepal. However, even at the high concentrations used for selection, Kan slowed but did not stop growth of strain 1295-22. Consequently, only about $10 \%$ of the putative $\mathrm{Kan}^{\mathrm{R}}$ strains were $\mathrm{Gus}^{+}$in this experiment.

The growth rates of wild-type and transformed strains were compared on PDA and CDA. On PDA, hygB ${ }^{R}$ strains T22/H303 and T22/H918 grew slower than the wild-type at $15^{\circ} \mathrm{C}$, and GUS-transformed strains G83-1-210 and G84-21-208 grew more slowly than the wild-type at $30^{\circ} \mathrm{C}$. However, on CDA there were no significant differences between strains at either 15 or $30^{\circ} \mathrm{C}$ (Table 1). Therefore, strains T22/H038, T22/H094, G83-1-210, and G84-21208 were used for further experiments.

The insertion of foreign plasmid DNA was detected in genomic DNA obtained from T22/H038, T22/H094, G83-1-210, G84-21208, and wild-type strain 1295-22, using dot blots. The genomic DNA of T22/H038 and T22/H094 hybridized with the hygB probe. The genomic DNA of G83-1-210 and G84-21-208 hybridized with the GUS probe. Wild-type genomic DNA did not hybridize with

TABLE 1. Mycelial growth rate of Trichoderma harzianum strain 1295-22 and its transformed isolates at 15 and $30^{\circ} \mathrm{C}$ on various media

\begin{tabular}{lccccc}
\hline & \multicolumn{4}{c}{ Mycelial growth rate $(\mathrm{mm} /$ day) } \\
\cline { 2 - 3 } \cline { 5 - 6 } Isolate $^{\mathrm{y}}$ & \multicolumn{2}{c}{ PDA $^{\mathrm{y}}$} & & \multicolumn{2}{c}{$\mathrm{CDA}^{\mathrm{z}}$} \\
\cline { 2 - 3 } \cline { 5 - 6 } 1295-22 & $10.5 \mathrm{ab}$ & $30.0 \mathrm{~b}$ & & $5.0 \mathrm{a}$ & $18.9 \mathrm{~b}$ \\
T22/H303 & $7.6 \mathrm{c}$ & $30.7 \mathrm{ab}$ & & $5.1 \mathrm{a}$ & $20.1 \mathrm{ab}$ \\
T22/H038 & $11.3 \mathrm{a}$ & $31.5 \mathrm{ab}$ & & $6.1 \mathrm{a}$ & $20.6 \mathrm{ab}$ \\
T22/H094 & $11.5 \mathrm{a}$ & $32.0 \mathrm{a}$ & & $6.0 \mathrm{a}$ & $21.0 \mathrm{a}$ \\
T22/H918 & $8.2 \mathrm{c}$ & $31.0 \mathrm{ab}$ & & $5.5 \mathrm{a}$ & $21.0 \mathrm{a}$ \\
G83-1-210 & $9.9 \mathrm{~b}$ & $23.5 \mathrm{c}$ & & $5.5 \mathrm{a}$ & $22.0 \mathrm{a}$ \\
G84-21-208 & $9.4 \mathrm{~b}$ & $21.5 \mathrm{~d}$ & & $5.2 \mathrm{a}$ & $21.1 \mathrm{a}$ \\
\hline
\end{tabular}

x $\mathrm{T} 22 / \mathrm{H}$ indicates hygromycin B-resistant transformants, and $\mathrm{G}$ indicates transformed strains containing genes for kanamycin resistance and expression of $\beta$-glucuronidase.

${ }^{y}$ In each column, numbers followed by the same letter do not differ significantly $(P=0.05)$ according to Duncan's multiple range test. Results are from one representative experiment.

${ }^{\mathrm{z}} \mathrm{PDA}=$ potato dextrose agar; CDA $=$ Czapek-Dox agar. 
either the $G U S$ or $h y g B$ probe (data not shown). Integration of transforming DNA into the genome of these transformants also was confirmed by Southern analysis. After digestion with HindIII, an intense homologous band similar to the size of $\mathrm{pHAT} \alpha$ in strains T22/H038 and T22/H094 and similar to the size of PBI121 in strains G83-1-210 and G84-21-208 was observed. There was no homology between the DNA from any parental strain and the hygB or GUS probes (data not shown).

The biocontrol abilities of wild-type and transformed strains were determined. Application of conidial suspensions of either the wild-type or transformed strains significantly reduced the severity of brown patch disease compared to disease severity in untreated flats and flats treated only with Triton X-100. There were no differences between any of the transformed strains (T22/H038, T22/H094, and G83-1-210) and wild-type strain 1295-22 (Table 2).

Comparison of colonization and survival of $\mathrm{hygB}^{\mathrm{R}}$ and wildtype strains of $T$. harzianum on creeping bentgrass. Two transformants, T22/H038 and T22/H094, and the original strain 1295-22 were compared for their ability to colonize and survive in situ after spray applications. Strains T22/H038 and T22/H094 colonized entire seedlings of creeping bentgrass as well as the original strain 1295-22.

In all cases, conidial sprays resulted in an increase in the population levels of Trichoderma spp. in both rhizosphere soil and on the phylloplane of creeping bentgrass (Fig. 1A1 through D1). The levels of colonization of both leaves and roots were similar in plants grown in autoclaved (Fig. 1B1 and D1) and unautoclaved soils (Fig. 1A1 and C1). The population levels of the hygB ${ }^{\mathrm{R}}$ and wild-type strains were similar in all treatments. All three strains persisted for the duration of the experiment (28 days) in the rhizosphere and in the leaf environment, although population levels declined somewhat over the course of the experiment in unautoclaved soils (Fig. 1A1 through D1).

By the end of the 28-day experiment, populations of Trichoderma spp. had increased in the nontreated controls to levels approaching those on the treated plants (Fig. 1A1 through D1). Consequently, it became impossible to determine whether effects of the treatment were due to application of conidial suspensions, proliferation of native strains, or cross-contamination from treated plants.

This ambiguity was readily resolved when experiments were performed with the hygB ${ }^{\mathrm{R}}$ strains. Background levels of Trichoderma spp. were reduced to 0 when dilutions from either the rhizosphere soil or the phylloplane were plated on TSM containing hygB at $700 \mu \mathrm{g} / \mathrm{ml}$ (Fig. 1A2 through D2). However, populations of hygB ${ }^{R}$ strains detected on TSM plus hygB after spray applications were very similar to populations obtained when either the original strain $1295-22$ or the hygB ${ }^{\mathrm{R}}$ strains were plated on TSM (Fig. 1).

These data indicated that (i) the hygB ${ }^{\mathrm{R}}$ strains possessed rhizosphere and phylloplane competence similar to that of strain 1295-

TABLE 2. Suppression of Rhizoctonia brown patch on creeping bentgrass by spray application of spore suspensions of Trichoderma harzianum strain 1295-22 and its transformed isolates in greenhouse experiments

\begin{tabular}{lccc}
\hline & \multicolumn{3}{c}{ Disease severity $(\%)^{\mathrm{y}}$} \\
\cline { 2 - 4 } Treatment & 0 days & 7 days & 21 days \\
\hline 1295-22 + Triton X-100 & 14.0 & 23.3 & 54.0 \\
T22/H094 + Triton X-100 & 15.0 & 16.7 & 49.3 \\
G83-1-210 + Triton X-100 & 13.0 & 16.7 & 48.0 \\
Triton X-100 & 12.0 & 31.3 & 68.7 \\
Water & 14.0 & 40.0 & 96.3 \\
LSD $(P=0.05)$ & 3.2 & 7.7 & 7.6 \\
\hline
\end{tabular}

y Percentage of flat occupied by diseased turf.

z T22/H094 represents hygromycin B-resistant transformants, and G83-1-210 represents transformed strains containing genes for kanamycin resistance and expression of $\beta$-glucuronidase. Results are from one representative experiment.
22, (ii) all, or nearly all, of the Trichoderma strains on creeping bentgrass sprayed with the hygB ${ }^{\mathrm{R}}$ strains were resistant to the antibiotic, (iii) the selection method for the resistant strains gave similar results to plating on TSM, and (iv) even though the population levels of Trichoderma spp. in the untreated control increased, indicating the presence of competing strains, these did not substantially affect or displace the populations of the hygB ${ }^{\mathrm{R}}$ strains.

Observation of GUS transformants on the roots and phylloplane of creeping bentgrass and their interaction with $R$. solani. In colonization tests on creeping bentgrass, plant samples from soil treated with $\mathrm{Gus}^{+} \mathrm{Kan}^{\mathrm{R}}$ strains were taken 1, 2, 3, 5, and 7 days after spray application. Samples were removed and treated with the X-Gluc substrate. Tissues were examined microscopically, and the presence of blue-stained transformed strains was noted. One day after spray application, numerous ungerminated conidia were found on or near leaves, roots, and seed coats of bentgrass seedlings. Two days after spray application, numerous hyphae and germ tubes of Gus ${ }^{+}$strains were seen on similar structures (data not shown). Hyphae were frequently found on and near leaves (Fig. 2B and C), seed coats (Fig. 2D), roots (Fig. 2E), root tips (Fig. 2F), and root hairs (data not shown) 3 to 7 days after treatment. Similarly, treatment of soil resulted in numerous Gus ${ }^{+}$ hyphae on roots and seed coats of creeping bentgrass. However, this treatment resulted in few or no hyphae on leaves (data not shown). In these experiments, no conidiation or other sporulation was observed; instead, only hyphae or ungerminated conidia were seen.

The interaction between the Gus ${ }^{+}$strain of T. harzianum (G831-210) and $R$. solani was evident in this study. $R$. solani colonized creeping bentgrass plants prior to application of the marked biocontrol strains, so numerous hyphae of the pathogen were evident on leaves but rarely were found on subterranean plant portions. Blue hyphae of $T$. harzianum were distinguishable from the hyphae of the pathogen, both in color and in size, because they were substantially smaller than those of the pathogen (Fig. 2). At 3 days after treatment, branching Gus ${ }^{+}$hyphae of $T$. harzianum frequently were observed on leaves and near hyphae of $R$. solani (Fig. 2A). At both 3 and 5 days after treatment, two types of reactions were found. In the first (type I), the Gus strain of $T$. harzianum grew near $R$. solani. Sections of some of the $R$. solani hyphae appeared necrotic and perhaps empty under phase microscopy in areas in which the $R$. solani hyphae came into contact with G83-1-210. The phenomenon also was seen at 3 days after application (Fig. 2B). The second type of reaction (type II) was typical of mycoparasitism. The hyphae of $T$. harzianum apparently coiled around and collapsed the hyphae of $R$. solani (Fig. 2C). This reaction was seen less frequently and was observed at sampling times earlier than 5 days after application of $T$. harzianum. In a separate experiment, we observed similar results when we examined the interaction between strain $1295-22$ and $R$. solani whose mycelia were stained with $0.1 \%$ cotton blue (data not shown).

\section{DISCUSSION}

Antibiotic resistance markers have been used widely to detect introduced bacteria and fungi in ecological studies $(24,28)$. As far as we know, Kan has not been used as a selectable marker for Trichoderma or other fungi. In this study, we found that Kan in high concentrations $(3,000 \mu \mathrm{g} / \mathrm{ml})$ reduced the mycelial growth rate of T. harzianum strain 1295-22 and helped select transformants of the strain. However, the antibiotic was not useful as a marker in ecological studies, because most Trichoderma spp. grew, albeit slowly, on media containing the antibiotic, even in high concentrations.

Transformed strains must be genetically stable and able to maintain their biocontrol activity after introduction to soil or foliage. Thrane et al. (36) suggested that measurement of physiological factors, including growth rate, was predictive of the biocontrol ability of Trichoderma. Results from our mycelial growth rate and 
biological control of brown patch disease tests indicated there may be a positive correlation between the growth rate and biocontrol ability of transformants. Consequently, it is important to compare the physiological traits and biocontrol ability of the evaluated transformants with original strains before carrying out time-consuming ecological studies.

Trichoderma spp. were detected $3 \mathrm{~h}$ after spray application, and conidia from Gus ${ }^{+}$strains were seen 1 day after treatment on all parts of creeping bentgrass plants, from the root tip to the uppermost leaf blade. This widespread distribution probably oc- curred because of the relatively high spray volume to surface area $\left(20 \mathrm{ml} / 100 \mathrm{~cm}^{2}\right)$ used. Creeping bentgrass plants are small, with a relatively dense but shallow root system, so the sporesuspension volume was adequate to allow $T$. harzianum to effectively colonize the entire root system. Conidia are easily carried by mass flow of water over the root surface in soil (4). Similarly, in field trials spray applications produced high levels of root colonization by T. harzianum strain 1295-22 (20).

Direct plating of root segments indicates the presence or absence of organisms but gives no information about the numbers of
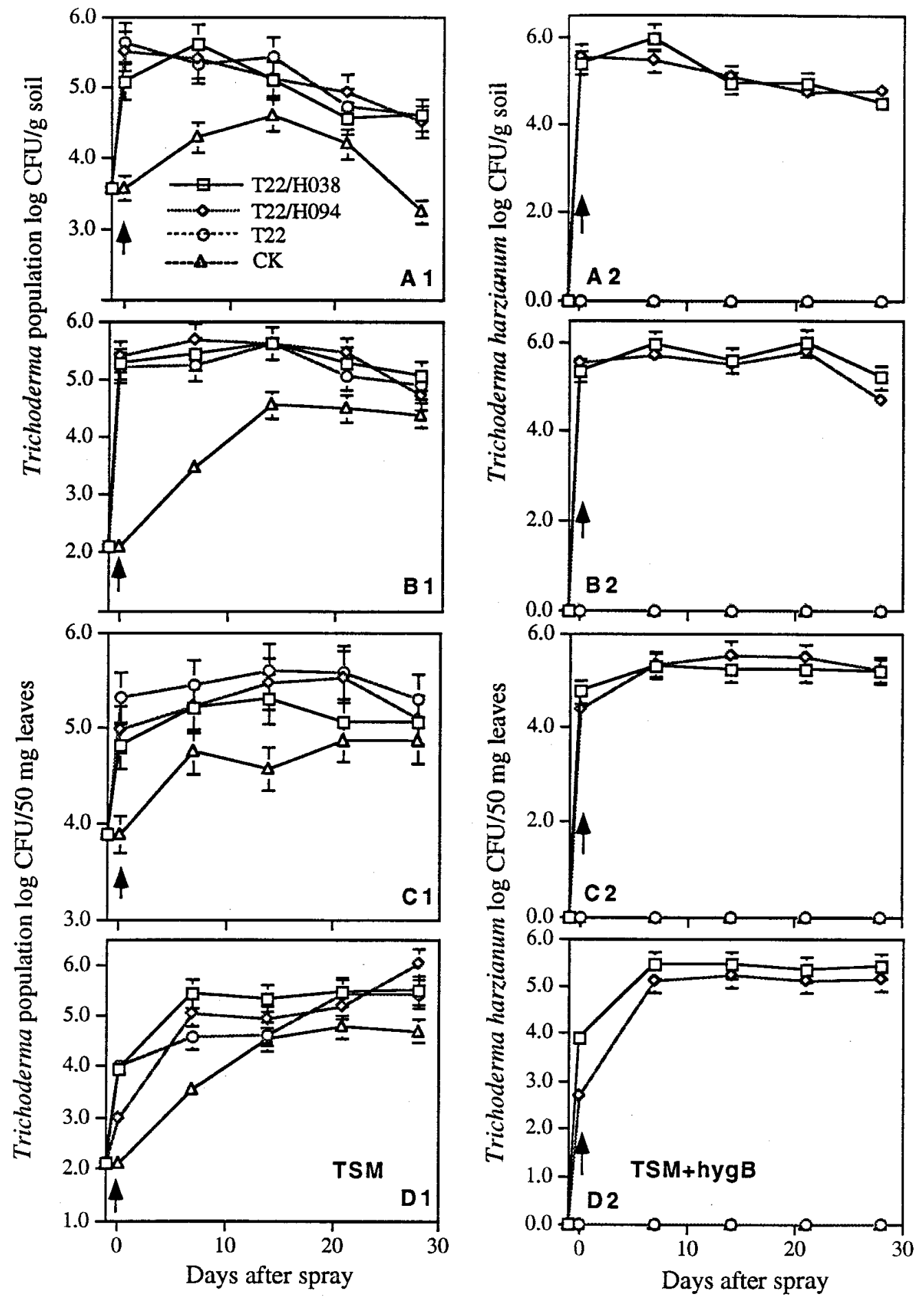

Fig. 1. Population dynamics of Trichoderma spp. and T. harzianum $\mathbf{A}$ and $\mathbf{B}$, in rhizosphere soils and $\mathbf{C}$ and $\mathbf{D}$, on the phylloplane of creeping bentgrass grown in either $\mathbf{A}$ and $\mathbf{C}$, unautoclaved soils or $\mathbf{B}$ and $\mathbf{D}$, autoclaved soils. Seedlings of creeping bentgrass were treated separately with a spray application of spore suspensions of strain T22/H038 (hygromycin B resistant $\left[\right.$ hygB $\left.^{\mathrm{R}}\right]$ ), T22/H094 (hygB ${ }^{\mathrm{R}}$ ), or wild-type 1295-22 (T22). Water was used as the check. A1 to D1, Population levels of Trichoderma spp. were detected with Trichoderma-selective medium (TSM), and A2 to D2, hygB ${ }^{\mathrm{R}}$ strains of T. harzianum were examined with TSM plus hygB at $700 \mu \mathrm{g} / \mathrm{ml}$. Arrows indicate Trichoderma levels $3 \mathrm{~h}$ after the spray application; the first value is the level prior to spraying. 
propagules on roots. Although dilution plating may be useful, colony-forming unit enumerations do not distinguish among propagules of different kinds (9). The occurrence of conidiation would give large differences in colony-forming unit levels that would not be representative of quantities of biomass. Harman (9), therefore, suggested that interpretation of colony-forming unit data must be done with caution.

In our experiments, both transformed and wild-type Trichoderma strains colonized and proliferated on all parts of creeping bentgrass plants for the duration of the experiments. For example, the
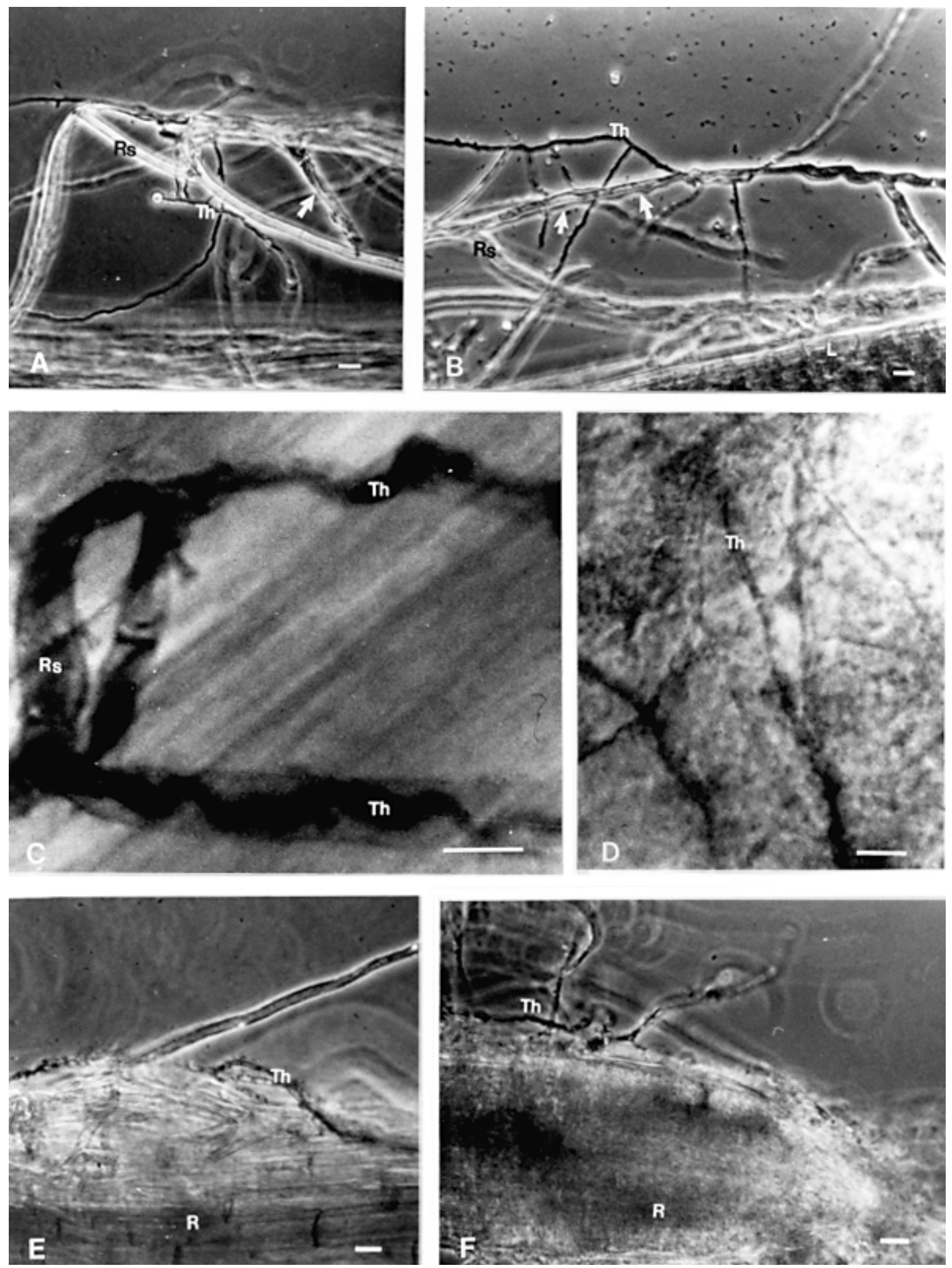

Fig. 2. Interactions between $\beta$-glucuronidase-transformed strain G83-1-210 of Trichoderma harzianum, creeping bentgrass, and Rhizoctonia solani, as observed by phase-contrast microscopy. Flats containing grass seedlings were inoculated with $R$. solani, and disease was allowed to develop. Subsequently, the grass was sprayed with a conidial suspension of strain G83-1-210 in an aqueous solution containing $0.1 \%$ (vol/vol) Triton X-100. A through C, Fungal growth on leaves of creeping bentgrass. Hyphae of the strain germinated and grew near mycelium of $R$. solani. A, One section of $R$. solani hyphae appeared necrotic (arrow) 3 days after treatment. B, Some sections of $R$. solani hyphae appeared necrotic and empty (arrow) in proximity to hyphae of the biocontrol agent 5 days after treatment. C, Mycoparasitism of the strain on $R$. solani hyphae. Hyphae of the strain growing on $\mathbf{A}$ through $\mathbf{C}$, the leaves; $\mathbf{D}$, the seed coat; $\mathbf{E}$, around the middle of the root and root hairs; and $\mathbf{F}$, the root tip. $\mathrm{Bar}=10 \mu \mathrm{m}$. $\mathrm{Rs}=R$. solani, $\mathrm{Th}=T$. harzianum, $\mathrm{L}=$ leaves, and $\mathrm{R}=$ roots. 
$\operatorname{hygB}^{\mathrm{R}}$ strains colonized all parts of creeping bentgrass. Microscopic observations indicated that $\mathrm{Gus}^{+}$strains germinated and colonized leaves, seed coats, and roots of plants 2 to 7 days after spray application. In addition, population levels of hygB ${ }^{R}$ or the native strains increased on the phylloplane between days 1 and 7 . These data indicated that the strains grew and proliferated on the leaf surface. Observation of Gus ${ }^{+}$strains also indicated that hyphae were produced and that leaves were colonized by those hyphae. There was no evidence for conidiation on plants over the duration of the experiment. Therefore, colony-forming unit values should be representative of biomass, because only hyphae were present. If conidia were produced, colony-forming unit values would not provide very useful data, because numbers of conidia, rather than quantity of biomass, would be the primary structures measured. Ahmad and Baker (2) found that quantitation of hyphae was relatively similar to colony-forming unit counts and that Trichoderma was present primarily as hyphae. Similarly, Green and Jensen (8) reported that their Gus ${ }^{+}$strain of $T$. harzianum was present on roots primarily as hyphae and not as conidia or other spore forms.

Dilution-plating on selective media often has been used for quantitative isolation of Trichoderma spp. from soil or other plant tissues (35). Introduction of a genetically marked isolate of $T$. harzianum into the environment allowed this biocontrol agent to be differentiated from indigenous isolates (24). In our studies, plating the washings from creeping bentgrass seedlings treated with hygB $^{\mathrm{R}}$ strains on TSM plus hygB gave values similar to those obtained when plants treated with strain $1295-22$ or hygB ${ }^{\mathrm{R}}$ strains were plated on TSM. Our results indicated that all strains remained at high levels. Colony-forming unit levels also increased on untreated control plants. With data from plating only on TSM, we could not distinguish whether strain 1295-22 remained the dominant strain over time or whether this strain was displaced by competitive Trichoderma strains from the environment. However, data obtained from plating on TSM plus hygB indicated that the transformants remained in the majority. Therefore, $\operatorname{hygB}^{\mathrm{R}}$ strains can be used to assess colonization by strain $1295-22$ in situ. These data support early reports that strain 1295-22 is rhizosphere and phylloplane competent $(12,20,34)$.

The GUS reporter gene from $E$. coli has been used to study the ecology of other pathogens and antagonists $(6,26,36)$. For example, Green and Jensen (8) recently demonstrated the suitability of using a GUS-transformed T. harzianum strain for monitoring its presence in the environment. In these experiments, blue-stained hyphae of $T$. harzianum were easily detected on plant roots. Our results also indicated that the Gus ${ }^{+}$strains were detected on roots, seed coat, and leaves of creeping bentgrass plants after spray application.

Direct interactions between $T$. harzianum and $R$. solani were clearly evident and changed over time. In type I reactions, sections of hyphae of $R$. solani appeared damaged, necrotic, and perhaps empty when the hyphae were in close proximity to the $\mathrm{Gus}^{+}$strain hyphae. This type I phenomenon also was observed in the interaction between Pythium spp. and T. harzianum by Lifshitz et al. (18). They (18) suggested that toxic factors produced by $T$. harzianum might play an important role in halting the pathogen, by causing plasmolysis of hyphal tip cells of the Pythium spp. before invasion and lysis. Clearly, damage also occurred to $R$. solani at a distance from the hyphae of $T$. harzianum. The factors that elicit such damage may include (i) extracellular enzymes released from $T$. harzianum that can diffuse to $R$. solani, (ii) water-soluble antibiotics, or (iii) volatile antibiotics.

It has been demonstrated that T. harzianum produces host walldegrading enzymes such as $\beta$-1,3-glucanases, chitinases, and cellulases, with the synthesis induced by the presence of host fungi or host wall components (11). These enzymes are toxic to a wide range of fungi (21). Recently, Benhamou and Chet (3) also reported that chitinases were involved in chitin breakdown and cytoplasmic aggregation of $R$. solani cells.
Water-soluble antibiotics also should be considered in the type I reaction. A role for such compounds has been considered unlikely for the mechanism of T. harzianum strain 1295-22, because no zones of inhibition characteristic of the presence of such compounds has been noted in paired culture tests. Peptaibols, however, are produced by other strains of $T$. harzianum only when induced by chitin and are repressed otherwise. Peptaibols cause membrane damage and could contribute to the effects seen in this study. Particularly, the antibiotics are synergistic with enzymes and are effective at low concentrations (33).

Finally, volatile antibiotics also could play a role. Graeme-Cook and Faull (7) reported that 6- $n$-pentyl-pyrone inhibited the mycelial growth rate of $R$. solani and other pathogens. Recently we found that strain 1295-22 also produces volatile substances that reduce the mycelial growth of $R$. solani in closed petri dishes (C.-T. Lo and G. E. Harman, unpublished data). The substance may contribute to the damage done to $R$. solani hyphae.

The data in this paper indicate that $T$. harzianum damages $R$. solani at a distance. However, there could be several mechanisms by which this occurs, and several kinds of metabolites toxic to $R$. solani may be produced by $T$. harzianum. The findings in this paper provide new insight into the reactions that occur between $R$. solani and T. harzianum, providing a basis for future research.

Another interaction, designated type II, also occurred. Type II is characterized by the coiling of $T$. harzianum around $R$. solani, which is typical of mycoparasitism. Mycoparasitism has been described primarily in in vitro studies. However, mycoparasitism by $T$. harzianum has been observed in situ on seed surfaces and sclerotia $(14,17)$. In this research, the type II reactions were observed less frequently, and the phenomenon was found no earlier than 5 days after treatment, whereas type I reactions were seen after just 3 days. Mycoparasitism, therefore, may represent a phenomenon that occurs after hyphae of $R$. solani are weakened during the type I interaction.

Taken together, our data indicate that transformants, including hygB $^{\mathrm{R}}$ and $\mathrm{Gus}^{+}$strains of T. harzianum, are useful tools for assessing the ecological traits of T. harzianum strain 1295-22, which include population development, colonization, and interactions with plant pathogens.

\section{ACKNOWLEDGMENTS}

We thank the Taiwan Agricultural Research Institute and the National Science Council of Taiwan (R.O.C.) for the financial support of C.-T. Lo. We also thank K. L. Ondik for assistance in editing the manuscript.

\section{LITERATURE CITED}

1. Adams, P. B. 1990. The potential of mycoparasites for biological control of plant diseases. Annu. Rev. Phytopathol. 28:59-72.

2. Ahmad, J. S., and Baker, R. 1987. Rhizosphere competence of Trichoderma harzianum. Phytopathology 77:182-189.

3. Benhamou, N., and Chet, I. 1993. Hyphal interaction between Trichoderma harzianum and Rhizoctonia solani: Ultrastructure and gold cytochemistry of the mycoparasitic process. Phytopathology 83:1062-1071.

4. Chao, W. L., Nelson, E. B., Harman, G. E., and Hoch, H. C. 1986. Colonization of the rhizosphere by biological control agents applied to seeds. Phytopathology 76:60-65.

5. Chet, I. 1987. Trichoderma: Application, mode of action, and potential as biocontrol agent of soil-borne pathogenic fungi. Pages 137-160 in: Innovative Approaches to Plant Disease Control. I. Chet, ed. John Wiley \& Sons, New York.

6. Couteaudier, Y., Daboussi, M. J., Eparvier, A., Langin, T., and Orcival, J. 1993. The Gus gene fusion system (Escherichia coli $\beta$-galactosidase gene), a useful tool in studies of root colonization by Fusarium oxysporum. Appl. Environ. Microbiol. 59:1767-1773.

7. Graeme-Cook, K. A., and Faull, J. L. 1990. Effect of ultraviolet-induced mutants of Trichoderma harzianum with altered antibiotic production on selected pathogens in vitro. Can. J. Microbiol. 37:659-664.

8. Green, H., and Jensen, D. F. 1995. A tool for monitoring Trichoderma harzianum. II. The use of a GUS transformant for ecological studies in the rhizosphere. Phytopathology 85:1436-1440. 
9. Harman, G. E. 1992. Development and benefits of rhizosphere competent fungi for biological control of plant pathogens. J. Plant Nutr. 15: 835-844.

10. Harman, G. E., Latorre, B., Agosin, E., Martin, R. S., Riegel, D. G., Nielsen, P. A., Tronsmo, A., and Pearson, R. C. 1996. Biological and integrated control of Botrytis bunch rot of grape using Trichoderma spp. Biol. Control 7:259-266.

11. Harman, G. E., and Nelson, E. B. 1994. Mechanisms of protection of seed and seedlings by biological control treatments: Implications for practical disease control. Pages 283-292 in: Seed Treatment: Progress and Prospects. T. Martin, ed. British Crop Protection Council, Nottingham, England, UK.

12. Harman, G. E., Taylor, A. G., and Stasz, T. E. 1989. Combining effective strains of Trichoderma harzianum and solid matrix priming to improve biological seed treatments. Plant Dis. 73:631-637.

13. Herrera-Estrella, A., Goldman, G. H., and Van Montagu, M. 1990. Highefficiency transformation system for the biological agents, Trichoderma spp. Mol. Microbiol. 4:839-843.

14. Hubbard, J. B., Harman, G. E., and Hadar, Y. 1983. Effect of soilborne Pseudomonas sp. on the biological control agent, Trichoderma hamatum, on pea seeds. Phytopathology 73:655-659.

15. Jefferson, R. A. 1987. Assaying chimeric genes in plants: The GUS gene fusion system. Plant Mol. Biol. Rep. 5:387-405.

16. Jefferson, R. A., Kavanagh, T. A., and Bevan, M. W. 1987. Gus fusion: $\beta$-glucuronidase as a sensitive and versatile gene fusion marker in higher plants. EMBO J. 6:3901-3907.

17. Jeffries, P., and Young, T. W. K. 1994. Interfungal parasitic relationships. CAB International, Wallingford, England, UK.

18. Lifshitz, R., Windham, M. T., and Baker, R. 1986. Mechanism of biological control of preemergence damping-off of pea by seed treatment with Trichoderma spp. Phytopathology 76:720-725.

19. Lo, C.-T., Nelson, E. B., and Harman, G. E. 1996. Biological control of turfgrass diseases with a rhizosphere competent strain of Trichoderma harzianum. Plant Dis. 80:736-741.

20. Lo, C.-T., Nelson, E. B., and Harman, G. E. 1997. Improved biocontrol efficacy of Trichoderma harzianum 1295-22 for foliar phases of turf diseases by use of spray applications. Plant Dis. 81:1132-1138.

21. Lorito, M., Hayes, C. K., Di Pietro, A., Woo, S. L., and Harman, G. E. 1994. Purification, characterization, and synergistic activity of a glucan 1,3- $\beta$-glucosidase and an $N$-acetyl- $\beta$-glucosaminidase from Trichoderma harzianum. Phytopathology 84:398-405.

22. Lorito, M., Hayes, C. K., and Harman, G. E. 1993. Biolistic transformation of Trichoderma harzianum and Gliocladium virens using plasmid and genomic DNA. Curr. Genet. 24:349-356.

23. McKenzie, L. I., Benzi, D., Dellavalle, D., and Gullino, M. L. 1991. Survival on the phylloplane of strains of Trichoderma spp. antagonistic to Botrytis cinerea. Petria 1:133-134.
24. Migheli, Q., Herrera-Esterella, A., Avataneo, M., and Gullino, M. L. 1994. Fate of transformed Trichoderma harzianum in the phylloplane of tomato plants. Mol. Ecol. 3:153-159.

25. Nelson, E. B., Burpee, L. L., and Lawton, M. B. 1994. Biological control of turfgrass diseases. Pages 409-427 in: Handbook of Integrated Pest Management for Turf and Ornamentals. A. Leslie, ed. CRC Press, Boca Raton, FL.

26. Oliver, R. P., Farman, M. L., Jones, J. D. G., and Hammond-Kosack, K. E. 1993. Use of fungal transformants expressing $\beta$-galactosidase activity to detect infection and measure hyphal biomass in infected plant tissues. Mol. Plant-Microbe Interact. 6:521-525.

27. Papavizas, G. C. 1985. Trichoderma and Gliocladium: Biology, ecology, and potential for biocontrol. Annu. Rev. Phytopathol. 23:23-54.

28. Parkinson, D., and Coleman, D. C. 1991. Methods for assessing soil microbial populations, activity and biomass. Agric. Ecosyst. Environ. 34:3-33.

29. Punt, P. J., Oliver, R. P., Dingemanse, M. A., and Pouwels, P. H. 1987. Transformation of Aspergillus based on the hygromycin B resistance marker from Escherichia coli. Gene 56:117-124.

30. Raeder, U., and Broda, P. 1985. Rapid preparation of DNA from filamentous fungi. Lett. Appl. Microbiol. 1:17-20.

31. Sambrook, J., Fritsch, E. E., and Maniatis, T. 1989. Molecular Cloning: A Laboratory Manual. Cold Springs Harbor Laboratory Press, Cold Springs Harbor, NY.

32. Sanford, J. C., Smith, F. D., and Russell, J. A. 1993. Optimizing the biolistic process for different biological applications. Pages 483-509 in: Methods in Enzymology, vol. 217. R. Wu, ed. Academic Press, San Diego, CA.

33. Schirmböck, M., Lorito, M., Wang, Y.-L., Hayes, C. K., Arisan-Atac, I., Scala, F., Harman, G. E., and Kubicek, C. P. 1994. Parallel formation and synergism of hydrolytic enzymes and peptaibol antibiotics, molecular mechanisms involved in the antagonistic action of Trichoderma harzianum against phytopathogenic fungi. Appl. Environ. Microbiol. 60:43644370 .

34. Sivan, A., and Harman, G. E. 1991. Improved rhizosphere competence in a protoplast fusion progeny of Trichoderma harzianum. J. Gen. Microbiol. 137:23-30.

35. Smith, V. L., Wilcox, W. F., and Harman, G. E. 1990. Potential for biological control of Phytophthora root and crown rots of apple by Trichoderma and Gliocladium spp. Phytopathology 80:880-885.

36. Thrane, C., Lübeck, M., Green, H., Degefu, Y., Allerup, S., Thrane, U., and Jensen, D. F. 1995. Tool for monitoring Trichoderma harzianum: I. Transformation with the GUS gene by protoplast technology. Phytopathology 85:1428-1435.

37. van Gorcom, R. F. M., Pouwels, P. H., Goosen, T., Visser, J., van den Broek, H. W. J., Hamer, J. E., Timerlake, T. J., and van den Hondel, C. A. M. J. J. 1985. Expression of an Escherichia coli $\beta$-galactosidase fusion gene in Aspergillus nidulans. Gene 40:99-106. 